\title{
El Instituto de Capacitación y Formación Social Sindical: una experiencia de formación político-sindical en un contexto de intensa conflictividad social (Argentina, 1963-1965)
}

\section{Gabriela Scodeller*}

Resumen: El presente artículo indaga en la relación entre formación política y acción sindical: ¿las instancias educativas son vistas como potenciadoras u obstaculizadoras de la lucha? Se analiza la experiencia del Instituto de Capacitación y Formación Social Sindical (ICFSS) creado por la CGT, y desarrollado simultáneamente al Plan de Lucha nacional que dicha central impulsó entre 1963 y 1965. Considerando los espacios de formación como un terreno de disputa en sí mismo, nos interesa complejizar el abanico de actores que allí jugaron. Nos preguntamos cómo y con qué objetivos se articuló una experiencia formativa a un contexto de intensa conflictividad social. Analizamos los contenidos desarrollados en el Instituto, particularmente la temática de la cogestión vinculada al proceso de ocupaciones fabriles.

Palabras clave: Educación político-sindical; cogestión; conciencia

\begin{abstract}
This article explores the relationship between political education and unions' actions: are formative instances seen as an enhancer or an obstacle for struggle? We analyze the experience of the Instituto de Capacitación y Formación Social Sindical (ICFSS) created by the CGT, and developed simultaneously with the national Plan de Lucha that this Confederation prompted between 1963 and 1965. Considering the spaces of workers' education as a terrain of struggle in itself, we intent to complex the range of actors who played in it. We wonder how and with what goals this learning experience was articulated to a context of intense social conflict. We analyze the contents developed in the Institute, particularly the issue of co-management linked to the factories' occupation process.
\end{abstract}

Key words: Political education; co-management; consciousness

* Conicet / IIGG-UBA. Contato: g_scodeller@yahoo.com.ar 


\section{Introducción}

Nuestra indagación gira en torno a la relación que se establece entre formación política y acción sindical, cómo se lleva adelante o profundiza la reflexión sobre o en relación a dicha práctica. Para nosotros la problemática de la formación político-sindical se ubica en un campo mayor que remite al proceso de formación/ recomposición de la clase obrera, y dentro de éste a la centralidad que ocupan las disputas políticas intragremiales. En este marco general, nos preguntamos por el lugar de las instancias formativas como potenciadoras u obstaculizadoras, como parte o aparte de la misma dinámica de lucha.

Desde una mirada que articula la concepción que parte de Marx por la cual las clases sociales se constituyen como tales en el proceso de enfrentamiento social, con aquella que proviene de la epistemología genética de Piaget donde el conocimiento se encuentra mediado por la acción', entendemos que hablar de conciencias obreras remite a un proceso nunca acabado y contradictorio, que se desarrolla fundamentalmente (aunque no únicamente) como resultado de la experiencia de lucha, pero cuya resultante no es unidireccional sino que puede asumir un carácter de superación o mantenimiento del orden establecido. Es precisamente este devenir abierto, el que habilita la pregunta por las formas en que la transmisión de la experiencia histórica o la reflexión sobre la práctica cotidiana -que ocurren mediadas por la formación político-sindical-tornean dicho resultado.

De allí que nuestro interés apunte a reconocer la importancia de las instancias de formación política en la profundización de la actividad práctica como primera instancia de toma de conciencia. Las entendemos como un momento dentro del proceso de toma de conciencia (práctico-teórico-práctico) ${ }^{2}$, que nos permite pensar la dinámica de reflexión sobre la propia práctica ${ }^{3}$, remite más específicamente al vínculo entre acción y conceptualización del que habla Piaget.

Nos interesa pensar cómo esta tarea es desarrollada por las propias instancias gremiales. Así, entendemos por experiencias de formación político-sindical aquellas que definen como interés o preocupación la preparación de cuadros, dirigentes o activistas sindicales para la intervención/acción gremial, sin seleccionarlas a priori por su orientación político-ideológica. Cómo estas tareas o rol del activista gremial (y por lo tanto el tipo de formación y su contenido) se amplíen o acoten, tendrá que ver con tradiciones ideológicas, contextos, etc. Aquí a su vez realizamos un recorte de nuestro objeto, al abocarnos a una experiencia sistematizada de formación, elaborada por una central obrera para los dirigentes y delegados de los sindicatos afiliados.

Como una primera aproximación al tema, indagaremos en la relación entre educación y lucha ubicándonos en un momento de alza de la conflictividad social. Para ello, en este artículo tomamos una experiencia desarrollada en Argentina entre los años 1963 y 1965, cuando desde la Confederación General del Trabajo (CGT)

1 Al respecto véase los trabajos de MARIN, Juan Carlos. Conversaciones sobre el poder. Una experiencia colectiva. Buenos Aires: IIGG-FCS-UBA, 1996; IZAGUIRRE, Inés y ARISTIZABAL, Zulema. Las luchas obreras 1973-1976. Buenos Aires: IIGG-FCS-UB, 2000; MULERAS, Edna. Sacralización y desencantamiento. Las formas primarias del conocimiento del orden social. Buenos Aires: Miño y Dávila, 2008.

2 Siguiendo a Piaget, pensamos el proceso de toma de conciencia en tres niveles/momentos que trazan un movimiento práctico-teórico-práctico. El primero indica un plano de la acción material sin conceptualización, pero cuyo sistema de esquemas constituye ya un saber elaborado; el segundo remite a un plano de la conceptualización, que obtiene sus elementos de la acción; y el tercero es un plano donde aparecen abstracciones y operaciones nuevas sobre la base de las anteriores, ahora compuestas y enriquecidas por la realización de combinaciones novedosas. PIAGET, Jean. La toma de conciencia. Madrid: Morata, 1976, pp. 254-274.

3 GRAMSCI, Antonio. El materialismo histórico y la filosofía de Benedetto Croce. Buenos Aires: Nueva Visión, 1997. 
se impulsaron dos importantes acciones. Por un lado, el Plan de Lucha que abarcó aquellos años y en el marco del cual se dio un extendido proceso de ocupaciones de establecimientos fabriles; por otro, la creación del Instituto de Capacitación y Formación Social Sindical (ICFSS). Nos interesa conocer cómo es que ambos procesos se articularon, complementaron y nutrieron entre sí, si es que efectivamente dicha vinculación existió o fue pensada explícitamente por las dirigencias sindicales y/o por el equipo de formadores de aquél entonces.

Es necesario destacar que tanto el Plan de Lucha de 1963-1965 como específicamente las ocupaciones de fábrica del año 1964 han sido profundamente estudiados. En general, los distintos autores que han abordado la temática se han manifestado en torno a un mismo eje de discusión: la mayor o menor planificación, organización y direccionalidad con que contó el proceso y vinculado a lo anterior, el mayor o menor peso y control de las cúpulas de las 62 Organizaciones Peronistas (rama político-sindical del movimiento) y la CGT entre las bases obreras, enfatizando en este caso un importante nivel de autonomía gremial a lo largo de todo el conflicto ${ }^{4}$. Sin embargo, ninguno articula dicho Plan de Lucha con la actividad sistematizada de formación que de modo paralelo impulsó la propia CGT. Tampoco se ha prestado atención a la importante tarea de propaganda realizada a través del Boletín Informativo Semanal de la CGT que fue editado durante esos mismos años.

Por otro lado, los escasos trabajos que refieren a la cuestión de la educación obrera suelen vincular experiencias como la que aquí referiremos a estrategias "pro-imperialistas" enmarcadas en el contexto de la Alianza para el Progreso, sin analizar su contenido ni cómo los programas internacionales de educación obrera fueron reapropiados, cuestionados o resignificados desde los actores locales 5 . Tampoco ha sido un tema abordado específicamente por quienes se han abocado a desentrañar el surgimiento y enfrentamientos entre las distintas líneas al interior del peronismo en esta época, siendo que las mismas poseían vinculaciones o influencias con las distintas corrientes existentes en el seno de la CGT.

Así, en este artículo pretendemos abordar un tema poco transitado por los historiadores del movimiento obrero como es el de la formación político-sindical, analizándolo como un terreno de disputa en sí mismo. En cuanto se refiere a la experiencia en particular, nos interesa ubicarla en el marco del Plan de Lucha y complejizar el abanico de actores que ocuparon este espacio. Nos preguntamos cómo y con qué objetivos se articuló una experiencia formativa a un contexto de intensa conflictividad social. Analizaremos los contenidos desarrollados en el Instituto, particularmente la temática de la cogestión vinculada al proceso de ocupaciones fabriles. Realizaremos dicha tarea a partir del análisis de distintas fuentes sindicales de la época. Incluimos también entrevistas orales realizadas a docentes y dirigentes gremiales que participaron de dicha experiencia.

4 Entre quienes destacan el rol de unificación jugado por la central obrera pueden consultarse los trabajos de COTARELO, M. Celia y FERNANDEZ, Fabián. La toma de fábricas. Argentina, 1964. Buenos Aires: PIMSA Documentos de Trabajo N², 1994; GRAU, M. Isabel, IANNI, Valeria y MARTI, Analía. Una aproximación a las acciones de la lucha de la clase obrera argentina. Primera etapa del Plan de Lucha de la CGT. 1963/1965. En: PIMSA 2004. Buenos Aires: PIMSA, 2004, pp. 100-124. En una línea que plantea un proceso de autonomía de las bases y de cuestionamiento y superación a la dirección de la CGT, véase SCHNEIDER, Alejandro. Los compañeros. Trabajadores, izquierda y peronismo, 1955-1973. Buenos Aires: Imago Mundi, 2005.

5 Al respecto véase: PARCERO, Daniel. LaCGT y el sindicalismo latinoamericano. Historia crítica de sus relaciones. Desde el ATLAS a la CIOSL. Buenos Aires: Ed. Fraterna, 1987; POZZI, Pablo. El sindicalismo norteamericano en América Latina y en la Argentina: el AIFLD entre 1961-1976. En: Revista Herramienta № 10, julio 1999; BOzZA, Juan. Trabajo Silencioso. Agencias anticomunistas en el sindicalismo latinoamericano durante la Guerra Fría. En: Revista Conflicto Social, Año 2, № 2, diciembre 2009. 


\section{El Plan de Lucha 1963-1965}

El proceso atravesado por el movimiento obrero peronista con posterioridad al golpe de estado de 1955 que derrocó a J.D. Perón abrió diversas perspectivas dentro del mismo. Por un lado, proscripto el partido, las dirigencias sindicales asumieron una representación que superaba lo estrictamente reivindicativo. Aunque en un continuo tire y afloje, algunos sectores lograron acumular cierto poder en el marco de apertura generada durante los gobiernos de Frondizi (1958-1962) e Illia (1963-1966). Por otro, muchos sectores obreros y juveniles comenzaron un proceso de resignificación del peronismo original, acercándose hacia posiciones clasistas. Fue el caso del Movimiento Revolucionario Peronista (MRP) de Gustavo Rearte - cuyo discurso logró cierta penetración entre sectores obreros en el contexto de las ocupaciones de 1964- o de la Acción Revolucionaria Peronista (ARP) de J.W. Cooke -que también cobró fuerza en esta época-.

1957 y 1962 habían visto surgir dos de los programas históricos de la clase obrera argentina, sintetizando el componente antimperialista que acompañaba el imaginario de los trabajadores por esos años. El segundo de ellos, el 'Programa de Huerta Grande', había sido elaborado por la denominada línea dura dentro de las 62 Organizaciones, encabezada por Andrés Framini (Textiles). Mientras esto sucedía Augusto Vandor, dirigente de los metalúrgicos y referente de la línea hegemónica dentro del sindicalismo peronista, se entrevistaba con el embajador norteamericano ${ }^{6}$. Su estrategia de 'golpear para negociar' se sostenía en las expectativas reivindicativas de los trabajadores, en quienes la propuesta más "socializante" del Programa de Huerta Grande no lograba ecoo.

Por su parte, a través de distintas intentonas militares, los sectores burgueses pretendían dirimir sus diferencias no sólo en materia económica y del modelo de acumulación a impulsar, sino en cuanto a qué hacer frente al peronismo y al movimiento obrero. En julio de 1963 había ganado el candidato de la Unión Cívica Radical del Pueblo, A. Illia, con apenas el $25 \%$ de los votos, continuando la inestabilidad política del periodo. En dicho contexto, entre 1963 y 1965 se desarrolló el Plan de Lucha de la CGT.

Luego de largas negociaciones, la central obrera había sido normalizada hacia fines de enero de 1963. Nucleaba a 234 asociaciones, sindicatos y federaciones a nivel nacional, lo que representaba 2 millones y medio de afiliados ${ }^{8}$. Políticamente quedó integrada por igual cantidad de miembros de las 62 Organizaciones y de los Gremios Independientes, aunque los principales cargos fueron para los primeros. José Alonso (Vestido) de las 62 ocupó el de Secretario General, mientras que Riego Ribas (Gráfico) del sector de los Independientes asumió como Secretario Adjunto.

En ese mismo congreso se anunció el Plan de Lucha denominado "El cambio total de las estructuras". Las exigencias del movimiento obrero organizado que motivaron el mismo eran: libertad de los presos sociales y políticos; derogación de las leyes represivas; solución al problema de los salarios y jubilaciones; participación de los trabajadores en los órganos de conducción de la vida económica; control de costos y fijación de precios máximos para los artículos de primera necesidad; anulación de los contratos petroleros; reforma agraria; retorno a la constitución; libertad de prensa, entre otros numerosos puntos.

6 CULLEN, Rafael. Clase obrera, lucha armada y peronismos. Génesis, desarrollo y crisis del Peronismo Original, Vol. I. Buenos Aires: De la Campana, 2008, p. 204.

7 Idem, pp. 209 y 211.

8 Datos extraídos de DE IMAZ, José L. Los que mandan. Buenos Aires: Eudeba, 1965, p. 224.

9 Puede consultarse en COTARELO, M. C. y FERNÁNDEZ, F., Op. Cit., pp. 8-9. 
Sin entrar en detalles sobre su desarrollo, nos interesa marcar brevemente las distintas etapas del Plan de Lucha y sus características, a los efectos de analizar su posible vinculación con el proceso de formación desarrollado desde el Instituto de Capacitación y Formación Social Sindical:

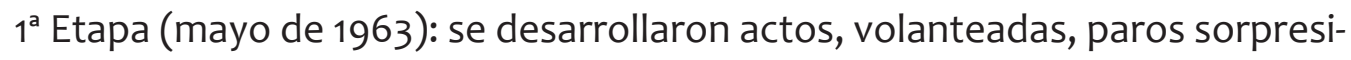
vos y manifestaciones durante una semana, las que culminaron en una huelga general de 24 hs. Hubo una importante tarea de difusión previa a través de mariposas y murales.

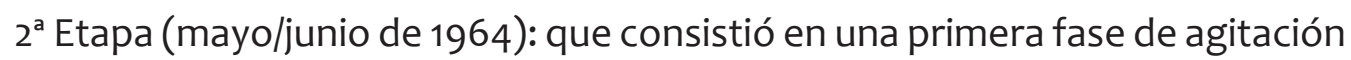
y esclarecimiento, y una segunda que fue cuando se produjeron las ocupaciones masivas de establecimientos fabriles. Aunque prevista para marzo, se postergó por la oposición de los gremios Independientes a su realización. Fueron, a lo largo de distintos operativos, 11.000 los establecimientos fabriles tomados, fundamentalmente en las zonas industriales de Capital Federal y Gran Buenos Aires, afectando a más de 3.913.000 trabajadores ${ }^{10}$.

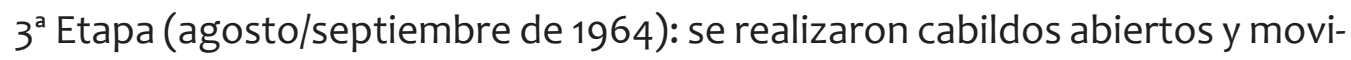
lizaciones en las principales ciudades del interior del país. Consistieron en actos públicos de los que participaron distintas organizaciones políticas y sectores sociales y en los que se realizaban análisis y propuestas en relación a la situación nacional. Tal vez por ello, cobraron centralidad los reclamos políticos, diluyéndose los de tinte netamente gremial.

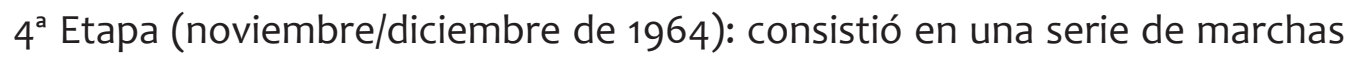
y movilizaciones, muchas de las que culminaron en enfrentamientos callejeros, y que finalizaron con una huelga general de 48hs.

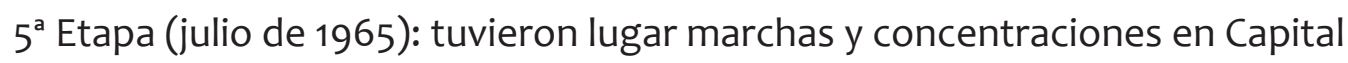
y Gran Buenos Aires y la realización de un acto en el mes de octubre. Ante la represión durante este último, se convocó a una huelga general en la que murieron tres obreros producto de enfrentamientos con la policía. Cabe señalar que en el mes de enero el Congreso Ordinario de la CGT Felipe Vallese había renovado las autoridades de la Confederación. Éstas declararon la vigencia y necesidad de seguir con el Plan de Lucha, actualizándolo a partir de nuevos objetivos ("Declaración de Reactivación del Plan de Lucha")"11.

Remarquemos la distancia de casi un año entre la primera y la segunda etapa del Plan de Lucha. Mientras que los análisis en general han adjudicado este paréntesis a los deseos de las 62 Organizaciones de intervenir en las elecciones previstas para mediados de 1963, nos interesa introducir la cuestión de la actividad educativa, y pensarla como un elemento más de este extenso Plan de Lucha. Fue justamente en el lapso temporal entre las dos primeras etapas, que se desarrolló con mayor sistematicidad e intensidad la experiencia del Instituto de Capacitación y Formación Social Sindical.

\section{La formación política para el "cambio de estructuras"}

Como mencionamos, el Plan de Lucha que el Congreso Normalizador aprobó en 1963 se denominó “El cambio total de las estructuras". Las referencias a esta

10 CGT. Memoria y Balance 1963-1964. Periodo de Febrero 1963 - Agosto 1964. Buenos Aires, 1964.

Cabe destacar la cobertura gráfica de las ocupaciones que se realizó en el Boletín Semanal. Dos números están enteramente dedicados a la cuestión, eligiendo relatar el conflicto visualmente a través de 137 fotografías. Véase CGT. Boletín Informativo Semanal. Buenos Aires: Mayo y Junio de 1964.

11 SCHNEIDER, A. Op. Cit., p. 234. 
cuestión suelen reducirse en la bibliografía a la elaboración de un folleto que data de 1965 titulado 'La CGT en marcha hacia el cambio de estructuras: juzga el pasado, analiza el presente y proyecta el futuro', existiendo cierto consenso en cuanto a que el mismo fue relegado e ignorado por el conjunto de la dirigencia cegetista. Sin embargo, más allá de esta formulación final como publicación de 84 páginas, la constante referencia a la idea del "cambio de estructuras" impregnaba la retórica de la época. Para abonar a la construcción de dicho proceso, fue concebida la necesidad de la formación.

Inmediatamente se impulsaron desde la Secretaría de Prensa, Cultura, Propaganda y Actas a cargo de Luis Angeleri (Luz y Fuerza), una serie de medidas en este sentido, que no apuntaron sólo a la formación de sus cuadros sino a la elaboración de información e investigaciones que sostuviesen sus planteos. Según J.L. De Ímaz (vinculado a J. Alonso), era la primera vez que los dirigentes de la CGT recurrían al asesoramiento de equipos técnicos especializados ${ }^{12}$. Se fundó así el Departamento de Economía Social, a cargo de O. Martini (quien junto a J. Villanueva dictaron las materias de perfil económico en el ICFSS). Se realizaron dos importantes Jornadas de debate: Económicas y Agrarias -cuyas publicaciones se agotaron-. Se inició un proceso de recuperación y compra de material bibliográfico ${ }^{13}$, tarea que estuvo a cargo de Guillermo Gordonez. Se editó el Boletín Informativo Semanal, cuya tirada por número era de 6.000 ejemplares ${ }^{14} \mathrm{y}$ desde agosto de 1964 se realizó un programa radial sobre "problemas nacionales, analizados a nivel popular" 15.

Entre esta batería de acciones tendientes a difundir información, potenciar debates y capacitar a los trabajadores para el rol protagónico que debían asumir en esta "etapa revolucionaria", se creó el Instituto de Capacitación y Formación Social Sindical. Aclaremos que el contenido otorgado a dicha "revolución" era la justicia social, el reparto equitativo de la riqueza producida y la activa participación de los trabajadores en todos los ámbitos de gobierno ${ }^{16}$. ¿Cuál era el tipo de dirigente que se buscaba para dicha etapa? Un sujeto preparado para "realizar una conducción de tipo moderno, realista y revolucionaria"17; no limitado a tareas sindicales (las que además debían incluir la esfera gremial, cultural y de capacitación) sino concernientes a la vida política nacional. Cabe señalar en dichos enunciados la impronta del "sindicalismo de acción múltiple" que propugnaba la tendencia que luego sería identificada como "participacionista".

Se realizó entonces una profusa difusión de la actividad del ICFSS a través de las páginas del Boletín Semanal, donde se comentaban sus objetivos y se invitaba a participar del mismo. Con esta tarea quienes lo impulsaban esperaban "obtener en poco tiempo un plantel extraordinario de compañeros capaces de asumir puestos de dirección y gobierno en cualquier momento"18, al punto de definir al Instituto

12 DE IMAZ, J. Op. Cit., p. 229. Contrariamente a la valoración positiva de De Imaz, R. Carri, criticó fuertemente a los intelectuales vinculados a Alonso, grupo que "apenas incidió en la elaboración de una línea política, a lo sumo le agrega cierto lenguaje “científico"', que por “hermético" no solo no tuvo ningún éxito concreto en el movimiento sindical sino que además, estas "teorías políticas complicadas" tendieron a neutralizarlo. CARRI, Roberto. Sindicatos y poder en la Argentina. Buenos Aires: Editorial Sudestada, 1967, pp. $133-135$

13 Durante estos años se compraron 624 libros, recibieron 1335 obras y publicaciones periódicas por donación y 131 por canje; siendo las consultas bibliográficas muy numerosas (3032 consultas). Datos extraídos de CGT. Memoria y Balance 1963-1964. Op. Cit., p. 371.

14 CGT. Memoria y Balance 1963-1964, Op. Cit., p. 357.

15 CGT. Boletín Informativo Semanal No 74. Bs. As.: 10 al 16 de agosto de 1964, p. 26.

16 CGT. Boletín Informativo Semanal Nº64. Bs. As.: 1 al 7 de junio de 1964, p. 20.

17 Circular $\mathrm{N}^{\circ} 32$. Bs. As., 23 de Julio de 1963.

18 CGT. Boletín Informativo Semanal № 26. Bs. As.: 9 al 15 de agosto de 1963, p. 10. 
como una "verdadera fábrica de dirigentes". El objetivo de largo alcance era la preparación técnica y política de sus "cuadros, que en el día de mañana tendrán puestos claves en el gobierno del pueblo y por el pueblo y para el pueblo"20. Estos planteos en torno a la necesaria preparación de los trabajadores para ser gobierno, el conocimiento de nuevos instrumentos y métodos adaptados a los constantes cambios, se repiten en numerosas ocasiones.

De igual modo, las notas referidas al ICFSS siempre se vinculaban al Plan de Lucha en el cual se encontraba embarcada la central obrera:

En el Plan de Lucha que tiene para llevar a cabo la Central Obrera, observamos que se va al fondo la cuestión, o sea la participación del trabajador en la distribución de la riqueza nacional, y para que ello sea una realidad, los trabajadores tendrán que ir al poder. La CGT, en ese sentido y como complemento de ese objetivo, ha creado el Instituto de Capacitación y Formación Social Sindical, con la idea de preparar esa élite de gobierno. Esa circunstancia no se hace como un mero medio de conformar técnicos, sino todo lo contrario; el Instituto en cuestión alberga materias que van hacia la profundidad del cambio del sistema imperante en la vida política, económica y social de nuestro país; la CGT ha tenido la delicada preocupación de conformar tanto el Instituto como los distintos cursos que en el mismo se desarrollan, estrechamente vinculados al Plan de Lucha que está en vigencia en los trabajadores argentinos ${ }^{21}$.

Previamente al ICFSS y como actividad preparatoria del mismo, se desarrolló entre agosto y noviembre de 1963 un curso de "Conducción Sindical". Las clases eran dos veces a la semana y los días viernes, dentro de un denominado "Ciclo de Conferencias', se realizaban disertaciones a cargo de los agregados laborales y culturales de distintos países y de funcionarios de organismos internacionales. Las materias desarrolladas fueron: Análisis e interpretación del proceso histórico y social argentino; Estructura económica y social argentina; Estructura y Técnica de la organización y conducción sindical; Programación y planeamiento del cambio de estructuras; Experiencia y cooperación internacional ${ }^{22}$. Estuvo destinado a dirigentes y si bien previsto inicialmente para 50 alumnos, del mismo participaron unos 90, provenientes de Capital Federal y Gran Buenos Aires ${ }^{23}, 7$ de los cuales fueron posteriormente becados a Estados Unidos, Israel y Alemania.

Por dar un ejemplo de los contenidos desarrollados, dentro de la materia 'Estructura y Técnica de la organización y conducción sindical' dictada por Julio C. Neffa, los puntos del programa eran: I. Orígenes y realidad del sindicalismo; II. El sindicalismo en el mundo y en América Latina; III. El sindicalismo moderno en Argentina; IV. Técnica de la conducción sindical. La bibliografía con la que se trabajaba era completa y variada, aunque la base eran una serie de autores jesuitas, como el libro de A. Sily -director del Centro de Investigación y Acción Social (CIAS)- 'La organización sindical'. Otros materiales de esta línea cristiana eran los 'Cuadernos de CLAEH' y los textos de E. Máspero o L. Lebret ${ }^{24}$.

19 CGT. Boletín Informativo Semanal No 19. Bs. As.: 22 al 28 de julio de 1963, p. 2.

20 CGT. Boletín Informativo Semanal No 26. Bs. As.: 9 al 15 de agosto de 1963, p. 11.

21 CGT. Boletín Informativo Semanal № 53. Bs. As.: 16 al 22 de marzo de 1964, p. 9.

22 CGT. Boletín Informativo Semanal No 19. Bs. As.: 22 al 28 de julio de 1963, pp. 5-7; CGT. Memoria y Balance 1963-1964, Op. Cit., pp. 373-378.

23 CGT. Circular $\mathrm{N}^{\circ} 32$, Op. Cit.

24 Véase PROF. JULIO NEFFA. Curso de Conducción Sindical. Bibliografía para los tres primeros capítulos del programa de Estructura y técnica de la organización y conducción sindical. Archivo del Sindicalismo Argentino 'Santiago Senén González' (UTDT), y Entrevista a Julio Neffa (Buenos Aires, agosto 2011). 
El Instituto propiamente dicho comenzó a funcionar en abril de $1964^{25}$. El Director general del mismo era el propio L. Angeleri, y la dirección y programación de los cursos estuvo a cargo de Nicanor Saleño, asesor de Alonso. Su objetivo era a la vez "capacitar a los trabajadores y a sus dirigentes para la solución de los problemas específicos de los trabajadores dentro del marco sindical” y "preparar a los dirigentes para una conducción tendiente a estructurar el sindicato para participar en el proceso de cambio de estructuras y en la nueva sociedad". Para ello, se realizarían "estudios e investigaciones sobre la estructura social, económica y cultural, así como de problemas específicos de los sindicatos y otros que afecten a los trabajadores y al país" ${ }^{26}$.

A este fin se desarrollaron paralelamente cuatro cursos: 'Conducción Sindical', 'Auxiliar Social Sindical', 'Administración Sindical' y ‘Periodismo Sindical'. Además de los contenidos específicos, existió un cuerpo de materias comunes a los cuatro: 'Sindicalismo' a cargo de Julio C. Neffa y Juan J. Taccone (Luz y Fuerza); 'Proceso histórico y social argentino' a cargo del abogado Gonzalo Cárdenas; y ‘Sociología', dictada por José Luis De Imaz, Floreal Forni, Atilio Borón y Héctor Goglio (los dos últimos fueron también docentes de 'Técnicas de Investigación Social') ${ }^{27}$.

Nos dedicaremos, por cuestiones de espacio, a los contenidos desarrollados dentro del 'Curso de Conducción Sindical’28. En sintonía con el objetivo específico proyectado para este curso, que era: "analizar la estructura social y económica del país y de los trabajadores. Determinar las pautas programáticas y el planteamiento del cambio estructural de la sociedad" ${ }^{29}$, es destacable el peso que ocuparon ciertos contenidos históricos y teóricos vinculados a aquella formación políticotécnica necesaria para llevar adelante el "cambio de estructuras". Transcribimos el programa completo ya que es elocuente al respecto:

1) SINDICALISMO - 1. Los orígenes de la organización profesional; 2. La revolución industrial y sus consecuencias; 3 . El nacimiento del movimiento obrero; 4. Las ideologías y el movimiento obrero en el siglo XIX; 5. La Primera Internacional. La Segunda Internacional; 6. La Revolución Rusa y la Tercera Internacional; 7. El movimiento obrero entre las dos guerras; 8. Las centrales sindicales internacionales; 9. El movimiento obrero en América latina; 10. El movimiento obrero argentino; 11. El sindicalismo moderno en la Argentina.

2) PROCESO HISTÓRICO Y SOCIAL ARGENTINO - 1. Política española en América; 2. Revolución de Mayo; 3. Unitarios y federales. Interpretación sociológica de los dos movimientos; 4. La organización institucional; 5. De Pavón al 80. La generación liberal; 6. La revolución liberal y mercantil; 7. Advenimiento de las clases medias al poder; 8. 1930. La vuelta al "régimen"; 9. 1943 y 1945; 10. Industrialización y desarrollo económico.

25 CGT. Circular N 82, Buenos Aires: 6 de marzo de 1964.

26 CGT. Instituto de Capacitación y Formación Social Sindical de la CGT. Programa de Cursos y Seminarios a realizarse en 1965. Buenos Aires: Secretaría de Prensa, Cultura, Propaganda y Actas, p. 1.

27 Véase listado de profesores en CGT. Instituto de Capacitación y Formación Social Sindical de la CGT. Programa de Cursos y Seminarios a realizarse en 1965. Op. Cit.

28 El desarrollo del curso durante el año 1964 tuvo características similares a las del año anterior, aunque se modificaron los invitados al Ciclo de Conferencias. Sin embargo, ya para el año 1965 se advierten una serie de modificaciones, como por ejemplo, la incorporación de nuevas materias. Aquí exponemos el programa correspondiente a esta última fecha.

29 CGT. Memoria y Balance 1963-1964, Op. Cit., p. 380 
3) SOCIOLOGIA - 1. Introducción: objeto de la sociología; 2. Conceptos básicos; 3. La estructura social; enfoques para su análisis; 4. La dimensión demográfica. Las migraciones en la Argentina; 5. El proceso de urbanización en nuestro país; 6 . La transformación de la estructura ocupacional argentina; 7. La estructura de clases en la Argentina; 8. El poder. Su estructura en nuestro país; 9. Las alternativas de cambio social en la Argentina y el papel del movimiento obrero.

4) PSICOLOGIA SOCIAL - Psicología individual: 1. Psicología. 2. Individuo y sociedad. 3. El proceso de socialización; Psicología social: 4. Tipos de relación con los otros. 5. El líder. 6. Efectividad de la labor del líder.

5) ECONOMÍA - 1. Introducción: qué es la economía; 2. Factores de la producción. Importancia del trabajo; 3. La producción. El problema del costo; 4. La teoría del consumo. Los precios. Su determinación; 5. Los distintos tipos de mercado; 6. La distribución. Renta de la tierra. Salario. Interés. Beneficio; 7. Ahorro. Consumo. Inversión en la economía nacional; 8. La contabilidad nacional. Renta nacional. Su determinación.

6) GEOGRAFÍA ECONOMICA ARGENTINA - 1. Los factores naturales en la economía argentina; 2. Región geográfica y zona económica; 3. La población; 4. Las comunicaciones y el transporte; 5 . Hidrografía; 6. Pesca y explotación forestal; 7. Energía eléctrica; su papel en el desarrollo; 8. Agricultura; 9. Ganadería; 10. Minería; 11. Industrias; zonas y sectores; 12. Comercio exterior; 13. Integración económica regional y cohesión interna.

7) ESTRUCTURA ECONOMICA ARGENTINA - 1. Análisis de la estructura y funcionamiento de la economía argentina; 2. Desarrollo económico. Objeto y modelos; 3. La economía argentina y su ubicación en el panorama mundial; 4. Técnicas de programación económica; 5 . Financiamiento del desarrollo económico

8) PLANIFICACION DEL CAMBIO DE ESTRUCTURAS - 1. Objetivos sociales del desarrollo; 2. Ideologías y valores implícitos; 3. Programas y realización del cambio; 4. Elementos para un plan de desarrollo nacional; 5. Evaluación de un posible plan de desarrollo; 6. Crítica a planes nacionales de desarrollo ${ }^{30}$.

Se mantuvo el esquema de trabajo que complementaba el cursado bisemanal con el 'Ciclo de Conferencias' (de asistencia obligatoria) donde expusieron distintos agregados laborales y culturales durante el primer año y referentes sindicales y académicos del ámbito nacional en el segundo ${ }^{31}$. Pero además se agregaron una serie de 'Seminarios Especializados'. A diferencia de las materias anteriores, aquí se advierte cierta afinidad con los temas propugnados por los organismos internacionales vinculados a la Alianza para el Progreso. Estos seminarios eran:

1. Objetivos sociales del desarrollo económico; 2. Economía de la empresa y cogestión; 3. Salario vital, mínimo y móvil y el costo de vida; 4 . Comercio exterior y ALALC; 5 . Seguridad social y servicios sociales sindicales; 6. Cambio de estructuras y reforma agraria; 7. Los sindicatos y el problema de la vivienda; 8. Desarrollo económico y desocupación; 9. Las conquistas sociales en los convenios colectivos de trabajo ${ }^{32}$.

30 CGT. Instituto de Capacitación y Formación Social Sindical de la CGT. Programa de Cursos y Seminarios a realizarse en 1965 . Op. Cit., pp. 6-9.

31 Los expositores fueron: H. Giberti, C. Cao Saravia, A. Cafiero, A. Ferrer, A. Sampay, J. Terza, J.L. de Imaz, J. Villanueva, J. Alonso. CGT. Boletín Informativo Semanal Nº 67. Bs. As.: 22 al 28 de junio de 1964, p. 5.

32 CGT. Instituto de Capacitación y Formación Social Sindical de la CGT. Programa de Cursos y Seminarios a realizarse en 1965 . Op. Cit., p. 31. 
Durante el Ciclo 1964, se realizaron además unas 'Jornadas Intensivas' de dos días, cuyo tema general fue "La CGT frente al cambio de estructuras: Programa y Estrategia”33. En 1965 se incorporaron además una serie de 'Cursos Intensivos' para graduados de años anteriores como 'Análisis de Estructura I (Argentina)' y 'Análisis de Estructura II (América Latina)'. Se dictó también un 'Curso Intensivo para Delegados Regionales' destinado a miembros de los Secretariados, y un 'Curso de Integración Latinoamericano’ para dirigentes nacionales y de las centrales latinoamericanas.

La proyección inicial de la formación preveía un alcance federal, aunque no llegó a realizarse con sindicatos del interior debido a la precariedad económica aducida por la misma central. Estaba destinada para tres niveles: activistas, dirigentes de base y dirigentes del orden nacional. Podían ser alumnos los afiliados a organizaciones confederadas (se exigía certificación y había cupos de dos representantes por organización). Salvo el curso de Conducción Sindical destinado solo a dirigentes, de los otros tres podían participar tanto dirigentes como activistas. Debían poseer ciertos conocimientos básicos en las materias a cursar, se requería además asistencia a todas las clases y la aceptación del reglamento interno del instituto. Entre quienes asistieron prevalecieron empleados, cuya edad no superaba los 45 años (84\%). El análisis del nivel educativo muestra que la mitad poseía primaria completa, sólo un $8 \%$ había concluido la secundaria y un $5 \%$ habían realizado estudios universitarios. Cabe destacar que sólo cuatro de un total de 170 alumnos (entre los cursos de Conducción y Auxiliares) habían realizado previamente algún tipo de formación sindical ${ }^{34}$.

Específicamente del curso de 'Conducción Sindical' se graduaron 31 dirigentes en 1963 y 28 en 1964. ¿Qué herramientas metodológicas adquirieron a lo largo de esta formación, más allá del contenido político-técnico? ¿Cómo fue pensado el proceso de enseñanza-aprendizaje, el vínculo docente-alumno y por añadidura, la relación dirigentes-bases? ¿Cuál era la concepción sobre los modos de construcción, transmisión y resignificación de conocimientos?

En cuanto a la metodología de trabajo adoptada en el espacio áulico ${ }^{35}$, poco se ha podido profundizar. Según de que curso se tratase, tuvieron una duración de cuatro a ocho meses. Las clases eran breves y se realizaban en horario de tarde. En general las mismas mantenían una dinámica expositiva por parte del docente, se buscaba no utilizar una jerga academicista sino recurriendo a un "buen apoyo de técnicas pedagógicas" 36 . Cada clase contemplaba un espacio para preguntas u opiniones al final, pero además existía un ámbito para la discusión y exposición a través del trabajo en comisiones, donde entre otras cosas, se pretendía que los participantes "apliquen los conocimientos adquiridos a la realidad que ellos mismos viven" 37 . Todos los cursos tenían un fuerte componente de elaboración propia, por cuanto los alumnos debían preparar proyectos en relación a las temáticas desarrolladas. Por ejemplo, en el curso de 'Auxiliar Social Sindical' debían realizar un estudio socioeconómico en una "villa de emergencia” y elaborar un proyecto

33 CGT. Boletín Informativo Semanal N ${ }^{\circ}$ 72. Bs. As.: 27 de julio al 2 de agosto de 1964, p. 17. Los docentes fueron: G. Cárdenas, J.C. Neffa, J.L. de Imaz, O. Martini, F. Forni, J.J. Taccone, J. Villanueva y L. Angeleri.

34 Datos extraídos de DE IMAZ, J. Op. Cit., pp. 226-227, en base al análisis de las fichas de inscripción de los participantes en los cursos de 1964.

35 Realizamos aquí una síntesis tomando en consideración las distintas instancias de formación (cursos, seminarios intensivos y especializados).

36 Entrevista realizada a Atilio Borón (Buenos Aires, agosto 2011).

37 CGT. Boletín Informativo Semanal № 72. Bs. As.: 27 de julio al 2 de agosto de 1964, p. 17. 
de "promoción de la comunidad"38. Una jornada de trabajo intensiva al final del cursado, preveía la evaluación y devolución por parte de los participantes de los contenidos desarrollados.

La CGT entregaba el "material didáctico" a los participantes (antología de textos y versiones mimeografiadas de las clases). Los docentes por su parte, adaptando la experiencia de las 'Fichas' de la carrera de sociología de la Facultad de Filosofía y Letras de la UBA, realizaban especies de resúmenes de los textos indicados en la bibliografía, en un lenguaje más sintético y didáctico ${ }^{39}$, mientras que los libros se encontraban a disposición en la Biblioteca de la CGT. No se habían implementado aún las técnicas de educación obrera que promovía la OIT, consistentes no sólo en herramientas didácticas escritas sino auditivas, visuales, exposiciones, actividades lúdicas, etc. ${ }^{40}$

¿Qué concepción acerca de la historia se desprende de los programas y los textos en general? Distintas notas del Boletín permiten advertir la valorización que hacían quienes promovían el ICFSS respecto del aprendizaje sobre las experiencias históricas, tanto de su propia clase como del de las otras clases. En este último sentido por ejemplo, las escuelas de capacitación que impulsaban empresarios y militares eran un modelo frente al cual el movimiento obrero podía y debía asumir similar tarea ${ }^{41}$. En cuanto a lo primero, las experiencias que remitían a la historia y presente de la propia clase, entendida en términos internacionales, eran un componente importante en los programas de estudio, lo que se explicaba de la siguiente manera: "Así como no podemos renunciar a nuestro pasado para comprender la realidad nacional, y no podemos desconocer la realidad actual y la misión de la clase obrera en la Argentina, no podemos cerrarnos a lo que han hecho los trabajadores en otros países" ${ }^{42}$. En cuanto a la concepción sobre qué tipo de historia tenía sentido difundir y discutir en las aulas del ICFSS, en la fundamentación de la materia de Historia Argentina se planteaba: "Más que amontonar fechas, que muy pronto se olvidan, será una orientación sobre las grandes líneas e ideas que conformaron la Nación, prestando especial atención a los aspectos sociales y económicos"43. Se buscaba así educar en concordancia con la idea que atravesó al Instituto desde su creación, esto es, que fuera una formación para la lucha, articulada al Plan en marcha; al punto que en el recuerdo de uno de los promotores de la experiencia, L. Angeleri, el ICFSS es ubicado como "una de las etapas del Plan de Lucha" ${ }^{4}$.

Seguidamente nos ubicaremos en el contexto de la $2^{\text {a }}$ etapa, cuando se produjeron las ocupaciones fabriles (mayo y junio 1964) para evaluar hasta dónde fue factible pensar formación y confrontación unitariamente.

\section{Ocupaciones y cogestión}

Una de las preguntas que queda sin responder revisando la bibliografía existente sobre las ocupaciones fabriles de 1964 es: ¿para qué se tomaron las fábricas? En este sentido, creemos que la revisión de las tareas realizadas desde el ICFSS

38 CGT. Memoria y Balance 1963-1964, Op. Cit., pp. 397-399.

39 Entrevista a Atilio Borón. Op. Cit.

40 Véase por ejemplo, OIT. La educación obrera y sus técnicas. Ginebra: 1965.

41 CGT. Boletín Informativo Semanal № 42. Bs. As.: 30 de diciembre de 1963 al 5 de enero de 1964, pp. 4-5.

42 CGT. Boletín Informativo Semanal $N^{\circ} 19$. Bs. As.: 22 al 28 de julio de 1963, p. 5.

43 Idem.

44 Conversación no grabada con L. Angeleri (Buenos Aires, agosto 2011). En 1970 se publica su libro 'Los sindicatos argentinos son poder' (Editorial Pleamar), donde desarrolla extensamente la relación entre participación y formación. 
puede mostrar una arista que supere aquellas miradas por las cuales estas acciones simplemente respondían a la táctica vandorista de 'golpear para negociar', se enmarcaban en la disputa de dicho dirigente con Perón, o perseguían el objetivo de desestabilizar al gobierno de Illia. Sin negar que estos intereses estaban presentes, creemos que se puso mucho más en juego. La acción de tomar posesión del lugar de trabajo constituye una avanzada obrera sobre un territorio ajeno, espacio que a los trabajadores les es "social y jurídicamente ajeno pero que sienten práctica y moralmente propio"45; constituye un cuestionamiento objetivo al régimen de dominación más allá de la conciencia acerca de dicha acción. Aunque poco resaltado en la bibliografía, según testimonios algunas de esas fábricas ocupadas continuaron produciendo:

Las tomas de fábrica se producen en una medida desmesurada. Nadie, nadie imaginó que se pudiesen tomar de ese modo las fábricas. Y en alguna de ellas, como un fenómeno también especial, no solo se las toma y queda paralizada la actividad, sino que en algunas comenzaron a ponerse en producción ( ) Para decirlo en palabras de la etapa era casi insurreccional. Que se pudiesen tomar alrededor de 15.000 establecimientos, y que además los trabajadores pusiesen a trabajar esas fábricas era preocupante ${ }^{46}$.

Cabe aclarar que desde 1962 se implementó la ocupación de fábricas como método de lucha de los trabajadores, más pertinente que los paros en un contexto de crisis económica y sobreproducción ${ }^{47}$. Por otro lado, recordemos que desde el inicio del Plan de Lucha se reclamaba la participación obrera en las esferas de conducción o dirección; anteriormente, el mismo Programa de Huerta Grande postulaba "implantar el control obrero sobre la producción". El ámbito de la formación no estuvo al margen de esta reivindicación. Cómo detallaremos a continuación, el tema de la cogestión obrera fue un contenido trabajado en los cursos entre otras instancias de discusión y debate. La pregunta es cómo esto se vinculó al proceso en marcha y logró (o no) potenciarlo.

Durante las 'Jornadas Económicas' impulsadas por la CGT en agosto de 1963 se analizaron casos como los de Suecia, Alemania y Checoslovaquia, en donde "es normal que la representación obrera participe en todos los niveles de la conducción" ${ }^{48}$. En el marco del Ciclo de Conferencias que acompañaba al Curso de Conducción Sindical -y que eran reproducidas para un público más amplio a través de las páginas del Boletín Semanal-, en septiembre expuso el agregado social alemán sobre "Obreros y empleados, su coparticipación en la República Federal Alemana"49. Asimismo, algunos dirigentes gremiales que ya habían realizado estos cursos viajaron en abril de 1964 a Alemania "con el fin de interiorizarse de diversos problemas laborales, entre ellos los de cogestión de las empresas"

Al mes del proceso de ocupaciones, en el marco del mismo Ciclo de Conferencias se llevó a cabo la disertación "Una experiencia de cogestión en la Argentina”, a cargo del abogado e integrante de la Comisión Jurídica de la CGT, José

45 IZAGUIRRE, Inés y ARISTIZÁBAL, Zulema. Las luchas obreras. 1973-1976. Buenos Aires: IIGG, FSOC-UBA, 2002, p. 52.

46 Entrevista a Armando Mattarazo (Buenos Aires, octubre 2005). Red de Archivos de Historia Oral de la Argentina Contemporánea, Instituto de Investigaciones Gino Germani (UBA). Las ocupaciones no fueron 15.000 sino 11.000 , según los propios datos de la CGT.

47 Véase SCHNEIDER, A. Op. Cit., pp. 194-197; CARRI, R. Op. Cit., pp. 100-122.

48 CGT. Boletín Informativo Semanal No 29. Bs. As.: 30 de setiembre al 6 de octubre de 1963, pp. 8-9.

49 CGT. Boletín Informativo Semanal №25. Bs. As.: 2 al 8 de setiembre de 1963, pp. 2-3 y 5.

50 Comunicado de Prensa N 385, Buenos Aires, 3 de abril de 1964. 
Terza. Éste comenzó afirmando que "el tema elegido tiene una estrecha relación con el Plan de Lucha" ${ }^{51}$. Políticamente, la cogestión fue presentada para un contexto de crisis social como una herramienta de pacificación. El orador desarrolló la experiencia de la Alemania Occidental de inicios de los años '50, particularmente en sus aspectos legales; argumentó que la Constitución Nacional Argentina amparaba la coparticipación obrera en la gestión. Describió luego una experiencia de cogestión desarrollada en una fábrica metalúrgica de Capital Federal hacia fines de 1963, en la cual se puso en práctica con adaptaciones dicha legislación europea. Sin embargo, y a pesar de la eficiencia lograda en términos de producción, desde la UOM local y la CGT se decidió la interrupción de la experiencia en abril por el avecinamiento de la $2^{\text {a }}$ etapa del Plan de Lucha; con lo cual contradictoriamente con lo postulado, se desvincula en la práctica un proceso que era presentado como unitario: la ocupación de los establecimientos fabriles y la participación en la esfera de la producción y la gestión.

Según uno de los docentes del ICFSS, J.C. Neffa, las ocupaciones perseguían un objetivo político, sin que fuera puesto en cuestión el poder patronal; faltos de una herramienta política por la proscripción del peronismo, las fábricas se convertían en el lugar desde el cual presionar ya sea por exigencias gremiales o políticas. Ello no quitó que como estas acciones sucedieron "en pleno curso de capacitación", fuera un tema que "se trataba en los cursos". Al respecto, este docente explica:

dábamos cursos sobre participación en la empresa, ¿no? La experiencia internacional de, no tanto los consejos obreros como sería el fondo más marxista, pero participación de los beneficios, participación en la gestión, participación en la propiedad ${ }^{52}$.

Ya posteriormente al proceso de ocupaciones masivas, en septiembre de 1965, entre los seminarios especializados se desarrolló uno titulado ‘Economía de la empresa y cogestión', también a cargo de Neffa. El mismo estuvo destinado a aquellos egresados de los cursos de Conducción Sindical y Auxiliar Social Sindical de los años 1963 y 1964. En un mes de duración, con cuatro horas semanales de cursado, el programa que se desarrollaba era el siguiente:

1. La empresa moderna. Descripción de la empresa moderna en el sistema capitalista desde los puntos de vista económico, humano, técnico, jurídico y de la seguridad social. Evaluación de esa realidad.

2. La empresa reformada. Descripción de la empresa reformada. Derechos del trabajador en la empresa: participación en el poder, participación económica.

3. La cogestión. Terminología y concepto. Métodos para la codeterminación. Contenido de la cogestión. Función de los sindicatos. Dos modelos de cogestión: en Alemania Occidental y en Yugoslavia.

4. La cogestión en la Argentina. Experiencias de cogestión en el país. La Constitución Nacional. Los convenios colectivos. Proyectos de Ley.

5. Formas de participación. En general: planificación del mercado, legislación, reglamentos, problemas que se plantean. En particular y respecto de nuestro país ${ }^{53}$.

51 CGT. Boletín Informativo Semanal No 72. Bs. As.: 27 de julio al 2 de agosto de 1964, pp. 4-11 y 14-15.

52 Entrevista a Julio Neffa. Op. Cit.

53 CGT. Instituto de Capacitación y Formación Social Sindical de la CGT. Programas de Seminarios Especializados a realizarse en setiembre de 1965. Op. Cit., p. 2. 
Como puede advertirse, eran modelos de cogestión las experiencias de Alemania Occidental y Yugoslavia; los que también circulaban internacionalmente en los seminarios de formación de la OIT y regionales de las confederaciones internacionales. Si bien el docente de este seminario destaca el interés que despertaba la experiencia Yugoslava ${ }^{54}$, las fuentes de la época muestran una mayor inclinación por parte de la CGT local hacia el modelo alemán.

En aquel momento en Yugoslavia había un sistema de autogestión. Entonces el tema de la autogestión en aquel momento bueno, era un tema que, exponíamos en clases y una cosa media entusiasmante para los sindicalistas ¿no?

¿Era una referencia?

Sí, sí, y había también muchos sindicalistas argentinos que fueron a Yugoslavia ¿no? De modo que, como era una forma de socialismo no soviético digamos, despertaba mucha simpatía ${ }^{55}$.

El trabajo final consistía en la elaboración por parte de los asistentes de las bases para un proyecto de ley sobre cogestión. Si bien el dictado de este seminario fue posterior al proceso de ocupaciones, podemos suponer que el mismo obedeció a la necesidad de reforzar determinados elementos que no lograron desarrollarse prácticamente en la experiencia de 1964. Consideramos que justamente en este sentido, constituye una reflexión sobre la propia práctica, y muestra una intencionalidad explícita por parte del grupo docente e impulsor del proceso de formación, de articular este ámbito de conceptualización al proceso de lucha en marcha.

\section{La formación como territorio de disputa}

La experiencia a la que aquí nos hemos abocado se ubica en el momento de esplendor del vandorismo, caracterizado generalmente en la bibliografía como tendencia burocrática, reformista, aliada de sectores de la burguesía industrial y de las Fuerzas Armadas. La hegemonía de este sector de "acción sin ideas" 56 ha soslayado una mirada historiográfica en el plano de las disputas político-ideológicas que entonces se jugaban al interior de la central obrera. Pero circularon contemporáneamente por la CGT de aquellos años distintos núcleos político-intelectuales, los que de modos más o menos sistematizados brindaron su influencia en el campo de la formación y disputaron el contenido de la misma.

Hemos identificado cuatro grupos, los que a su vez actuaron en una no poco compleja relación entre ellos. El primero que mencionaremos, provenientes de una tradición de izquierda, es quizás el que participó de un modo menos formalizado en la propia experiencia del ICFSS. El segundo grupo, vinculado al vandorismo y a ciertos sindicatos del nucleamiento de los Independientes, permite advertir la presencia de la corriente internacional del 'Sindicalismo Libre'. Otros dos fueron los que más fuertemente pusieron su impronta al ICFSS, no sin matices entre ellos. El tercer grupo conformado por quienes desde la esfera sindical impulsaron la formación, provenientes del sindicato de Luz y Fuerza y relacionados con el propio

54 Véase la nota de su autoría "Autogestión obrera. La experiencia yugoslava”, aparecida en la revista Dinamis N²2 (órgano de prensa del Sindicato de Luz y Fuerza de Capital), de julio de 1970, pp. 40-46.

55 Entrevista a Julio Neffa, Op. Cit. Cabe señalar que al menos dentro de los dirigentes becados por la CGT, durante estos años no aparecen viajes a dicho país. CGT. Memoria y Balance 1963-1964, Op. Cit., pp. 362-364.

56 Entrevista a Miguel Gazzera (Buenos Aires, septiembre 2005). Red de Archivos de Historia Oral de la Argentina Contemporánea, Instituto de Investigaciones Gino Germani (UBA). 
secretario general de la CGT; y un cuarto grupo, integrado por el equipo de formadores que llevó adelante las tareas pedagógicas, procedentes en su gran mayoría de experiencias previas de capacitación vinculadas al sindicalismo cristiano.

El primer núcleo de intelectuales estuvo integrado por el Grupo CONDOR (Centros Organizados Nacionales de Orientación Revolucionaria), quienes claramente se definían como marxistas y peronistas. Cuatro de los miembros fundadores provenían de la Juventud Peronista (JP): Juan Hernández Arregui, Eduardo Duhalde, Rodolfo Ortega Peña y Oscar Balestieri, mientras que igual número lo hacían de la corriente de izquierda nacional ligada a Abelardo Ramos: Alberto Belloni, Ricardo Carpani, Rubén Bortnik y Rubén Borello57. Si bien estos cuestionaban a la burocracia cegetista, mantenían vínculos políticos e inclusive económicos - ya que recibían financiamiento para algunas de sus actividades y publicaciones ${ }^{58}$-.

En un documento de junio de 1964 ( $2^{\text {a }}$ etapa del Plan de Lucha) explicitaban como uno de sus objetivos el de "elevar con el aporte de su labor teórico-política, en primer lugar, el nivel político de los dirigentes sindicales y militantes obreros" 59 . Efectivamente, R. Ortega Peña y E. Duhalde se desempeñaron como asesores legales durante las ocupaciones de fábricas. En estos años además pueden verse las ilustraciones de R. Carpani acompañando las páginas del Boletín Informativo Semanal de la CGT. Asimismo, puede suponerse la influencia de este grupo al rastrear los títulos editoriales adquiridos por la Biblioteca de la central en estos años, con gran presencia de autores vinculados a la izquierda nacional. Se adquirieron obras de Ricardo Carpani, Jorge Spilimbergo, Arturo Jaureche, Manuel Ugarte, Federico Engels, León Trotsky, Jorge Abelardo Ramos, Carlos Kautsky, Alberto Belloni, Rodolfo Puiggrós, José Hernández Arregui, José María Rosa, entre otros.

El segundo grupo lo constituyó el vandorismo. Si bien el del ICFSS no fue un espacio considerado importante por la línea hegemónica dentro del movimiento obrero de la época, sí estuvo interesada en la construcción de una serie de vínculos internacionales. En el contexto post Revolución Cubana en que el 'Sindicalismo Libre' buscó ampliar sus redes de influencia en América Latina y se vio obligado a reformular su mapa de aliados superando su tradicional antiperonismo, puede comprenderse cierta confluencia del vandorismo con aquellos gremios que históricamente habían estado vinculados a la corriente promovida por el sindicalismo norteamericano -Riego Ribas y Antonio Mucci (Gráficos), Francisco Pérez Leirós (Municipales de Capital Federal) y Armando March (Comercio)-. Por lo tanto, ésta también fue una manera de intervenir en la direccionalidad ideológica que se otorgaba a los cursos. Concretamente, la influencia de este sector se ve en el desarrollo del 'Ciclo de Conferencias' ya desde 1963, y en los viajes de los egresados en calidad de becados a distintos países del bloque capitalista.

En relación a lo primero, participaron como expositores agregados laborales o culturales de Francia, Israel, Italia, Estados Unidos, Alemania Occidental, Inglaterra, República Árabe Unida, España, México, Brasil, y expertos de la OIT y

57 EIDELMAN, Ariel. Militancia e historia en el peronismo revolucionario de los años 60: Ortega Peña y Duhalde. Buenos Aires: Ediciones del CCC-Cuadernos de Trabajo N 31, 2004, p. 29.

58 Ortega Peña y Duhalde se relacionaron tanto con Framini (más orgánicamente) como con Vandor (no sólo porque se desempeñaban como abogados de la UOM, sino porque mantenían reuniones semanales con el dirigente). Idem, pp. 19-24.

59 'Manifiesto preliminar al país', Buenos Aires, junio de 1964. Véase en BASCHETTI, Roberto. Documentos de la Resistencia Peronista. 1955-1970. Buenos Aires: de la Campana, 1997, pp. 392-399. 
de la CEPAL. Cabe destacar la disertación del agregado laboral de Estados Unidos, Henry Hammond ${ }^{60}$, personaje fuertemente criticado por su vinculación con los servicios de inteligencia de su país. En cuanto a los viajes, entre 1963 y 1964 el Instituto otorgó 34 becas a "Ios mejores calificados" 61 , para realizar actividades de "capacitación y perfeccionamiento" o "estudios laborales" que fueron costeadas por las instituciones convocantes. Durante uno a tres meses, los becados visitaron los siguientes destinos: Ginebra (1); Perú (4); Puerto Rico y Estados Unidos (19); EE.UU. (5); Israel (2); Alemania e Israel (2); México (1) ${ }^{62}$. En otro ámbito, entre los principales donantes de libros a la Biblioteca de la CGT se encontraban: Estados Unidos, Alemania, Israel, México y los Organismos Internacionales. En esta época TEA fue una editorial dedicada a publicar libros de sindicatos norteamericanos traducidos al español, que estaba financiada por el gobierno de EE.UU. Según el testimonio de J. Neffa, el bibliotecario de la CGT era quien coordinaba las tareas de dicha editorial, siendo el nexo por el cual los sindicalistas recibían numerosas publicaciones de esta corriente ${ }^{63}$.

Estos factores llevaron a la acusación - desmentida enfáticamente por la Secretaría de Actas de la CGT- de que "tanto los alumnos como las materias, las dictamina la embajada de los EE.UU., como asimismo, la financiación de dichos cursos" ${ }^{64}$. Según Angeleri, el Instituto Americano para el Desarrollo del Sindicalismo Libre (IADSL) daba cursos y tenían buenas relaciones con la CGT en aquella época, aunque "eran otra cosa" 65 . Sin embargo, los vínculos con el denominado sindicalismo libre existieron, particularmente en materia de formación. Por ejemplo, en una carta que B. Ibáñez, director del Instituto Interamericano de Estudios Sindicales (IIES) de la ORIT-CIOSL, escribió a J. Alonso agradeciéndole el "fraternal intercambio de información", se refería al programa de los cursos que en ese momento se desarrollaban en la CGT, a la vez que prometía enviarle los programas y materiales de los cursos dictados en México ${ }^{66}$. Cabe además recordar que si bien en esta época la CGT no era parte de ninguna organización internacional, mantuvo relaciones con las tres existentes (Confederación Internacional de Organizaciones Sindicales Libres - CIOSL-, Confederación Internacional de Sindicatos Cristianos -CISC-, Federación Sindical Mundial -FSM-); aunque a través de la adhesión de los sindicatos a las Federaciones Sindicales Internacionales, sí existió mayor vínculo con la CIOSL.

El tercer grupo estaba integrado por hombres provenientes del Sindicato de Luz y Fuerza de Capital, en quienes la preocupación por las cuestiones referidas a

60 Su conferencia puede leerse en CGT. Boletín Informativo Semanal Nº32. Bs. As.: 21 al 27 de octubre de 1963 , pp. 3-6 y 10.

61 BELLONI RAVEST, Hugo. Educación sindical en la Argentina. Experiencias sobre capacitación obrera en España y Francia. Buenos Aires: S/E, 1973, p. 13.

62 CGT. Memoria y Balance 1963-1964, Op. Cit., pp. 362-364.

63 G. Gordonez dirigió una colección en la Editorial Pleamar que publicó títulos de Julio Neffa, Luis Angeleri y Rubén Rotondaro (director del IADSL en los años 70).

64 CGT. Boletín Informativo Semanal N 43. Bs. As.: 6 al 12 de enero de 1964, p. 4.

65 Entrevista a L. Angeleri, Op. Cit. Creado en 1962, no está claro cuando el IADSL comenzó a funcionar como tal en Argentina. Según S. Romualdi, ello sucedió hacia fines de 1963. ROMUALDI, Serafino. Presidentes y trabajadores. Memorias de un Embajador Sindicalista en América Latina. S/L: S/Ed., 1971, p. 419. Según la entrevista realizada por D. Parcero a Eleuterio Cardozo, recién lo hizo hacia fines de 1964. PARCERO, D., Op. Cit., p. 117. En esta última fecha coinciden las notas periodísticas del propio instituto y los informes del North American Congress on Latin America. Véase respectivamente AIFLD. The AIFLD Report Vol. 7, № 9. Washington: septiembre de 1969, pp. 36-37 y NACLA. Argentina in the hour of the furnaces. Nueva York: NACLA, 1975.

66 Carta de Bernardo Ibáñez a José Alonso, México D.F., 8 de octubre de 1963, International Institute of Social History (IISH), ICFTU Archives, Carpeta 5051. 
la formación era palpable -y tuvo su mayor fruto en la experiencia de cogestión de la empresa estatal de electricidad SEGBA en 1973-. Fue una de las pocas instituciones gremiales que desarrolló tareas sistematizadas de formación política y técnica, funcionando desde 1962 el Instituto de Capacitación Sindical de Luz y Fuerza. En el mismo se realizaban jornadas y cursos de capacitación para delegados, cursos especiales para dirigentes, “todos con el apoyo pedagógico de proyecciones cinematográficas, apuntes didácticos, mesas redondas, conferencias, y una excelente biblioteca especializada" ${ }^{67}$. Funcionó también un área dedicada a realizar estudios e investigaciones.

No por casualidad el responsable de la secretaría que llevó adelante el ICFSS provenía del Sindicato de Luz y Fuerza, aunque el conjunto de las actividades mencionadas contaron con un fuerte respaldo del Secretario General de la CGT, J. Alonso. Hombres vinculados a ambos espacios ocuparon puestos claves en el ICFSS, como coordinadores (Nicanor Saleño) o como docentes de materias troncales (Juan J. Taccone; José L. de Ímaz ${ }^{68}$ ). Aunque no constituyeron un grupo homogéneo políticamente ${ }^{69}$, sí compartían una misma estrategia política y concepción sobre el lugar de los ámbitos de formación en la misma:

Los cambios de estructuras, la revolución social, la toma del poder, etc. etc., han de venir por dos procedimientos, revolución violenta o revolución evolucionista. La primera no precisa gran comentario porque es elocuente por sí sola; en éste aspecto, no se precisa declamarla tanto sino realizarla de acuerdo a las posibilidades que existan para concretarla. En cuanto al segundo procedimiento para concretarla, es necesario trabajar, vale decir, concretar todo lo teórico en la práctica70.

Embarcados en esta "revolución pacífica, que se logra mediante el campo evolutivo", a través de la concreción de obras sociales, quienes se alinearon detrás del 'Sindicalismo de acción múltiple' promovido por el núcleo lucifuercista, lo pensaron como medio para lograr "compartir el poder"71. Estos no eran sino los preceptos de la corriente sindical más conocida como participacionista72, que comenzaba a tomar fuerza en la década de 1960 de la mano del Sindicato de Luz y Fuerza Capital. Era un sindicalismo que asumía tareas sociales, culturales, económicas y políticas y elaboró su propio proyecto político de alcance nacional. En este sentido pregonaba la negociación y participación en instancias de gestión tanto estatales como empresarias. La concepción de los sindicatos y su rol en la sociedad estaba impregnada por los preceptos de la doctrina social de la iglesia y la peronista. Nótese además los puntos de encuentro entre el deseo de impulsar un sindicalismo ‘moderno' y la apelación a una ‘revolución pacífica' con los planteos difundidos por los organismos alineados con la Alianza para el Progreso.

67 BELLONI RAVEST, H., Op. Cit., p. 15.

68 De Imaz había sido propuesto por la CGT. Como ya mencionamos, al igual que Saleño estaba vinculado a Alonso. Entrevista a Julio Neffa. Op. Cit.

69 Posteriormente, cuando Alonso es destituido de la CGT, el cargo de secretario general va a ser ocupado por un lucifuercista, Francisco Prado. 1966, los encuentra a todos apoyando el golpe cívico-militar, aunque desde nucleamientos político-sindicales diversos.

70 CGT. Circular $\mathrm{N}^{\circ} 32$, Op. Cit., p. 1.

71 GT. Boletín Informativo Semanal №64. Bs. As.: 1 al 7 de junio de 1964, pp. 20-21.

72 Véase al respecto los desarrollos teórico-políticos elaborados por su principal referente J.J. Taccone, en Crisis... respuesta sindical. Buenos Aires: Editorial Delta, 1971 y 900 días de autogestión en SEGBA: una experiencia argentina en participación. Buenos Aires: Fundación 2001, 1976. 
Finalmente, la presencia del cuarto grupo sería definitoria en la estructuración de los cursos y seminarios y en la elaboración de contenidos, nos referimos al equipo de profesores que actuaron de modo permanente acompañando el proceso de enseñanza-aprendizaje. El cuerpo central de docentes provenía de una experiencia de formación sindical nacida en 1956 y denominada 'Instituto de Formación Social Sindical' (IFSS), el cual estuvo vinculado a los sindicatos de orientación cristiana agrupados en Acción Sindical Argentina (ASA) -alineados a su vez con la Confederación Latinoamericana de Sindicalistas Cristianos (CLASC) ${ }^{73}$-. Integraban además el Centro Argentino de Economía Humana (CAEH), corriente fundada por L. J. Lebret, y mantenían fuertes vínculos con sus pares de Uruguay del Centro Latinoamericano de Economía Humana. Sus principales figuras eran Floreal Forni, Gonzalo Cárdenas -posteriormente uno de los principales referentes de las cátedras nacionales ${ }^{74}$ y Julio Neffa ${ }^{75}$. Contemporáneamente, R. Carri definió la tarea de lo que denomina el "grupo de ideólogos allegados a Alonso" como un intento por conjugar concepciones clásicas del peronismo y del sindicalismo, como la justicia social y el nacionalismo económico, con una fundamentación desarrollista socialcristiana ${ }^{76}$.

La llegada de este grupo al ICFSS remite a su participación en las actividades de formación del Sindicato de Luz y Fuerza. A partir de dicha relación es que fueron convocados a organizar el ICFSS. Efectivamente, el grupo de CAEH compartía cierto horizonte político con el anterior:

la perspectiva es la perspectiva cercana al peronismo, ¿no? Y lo que buscábamos era, como le puedo decir, un sindicalismo que tuviera más poder dentro de la sociedad, dado que el partido peronista estaba proscripto; de alguna manera que los sindicatos fueran reconocidos, que tuvieran participación; que hubiera un Consejo Económico Social, que hubiera, un instituto de planificación económica donde los sindicatos tuvieran su representante; y que en las empresas se peleara por la participación, que los sindicatos tuvieran algo que decir con respecto a la gestión de la empresa. Eso es lo que buscábamos ${ }^{77}$.

Pero también existían distintas matrices político-ideológicas que coexistían al interior del mismo equipo de formadores. Esto es claro por ejemplo en torno a una cuestión central del proceso como fue el de la cogestión. Como vimos en el apartado anterior, algunos se ubicaban más próximos a la noción de bien social de la empresa y de participación recortada afín a la doctrina social de la iglesia -en la que también abrevaban los dirigentes de Luz y Fuerza-, otros se encontraban más cercanos a la idea marxista de control obrero:

justificábamos la necesidad de aumentar el poder de la clase obrera en el manejo de las empresas, creíamos en la cogestión de las empresas, creíamos de alguna manera que había que avanzar en alguna forma de

73 Poco se ha escrito sobre esta línea dentro del sindicalismo argentino, al respecto puede consultarse OBERLIN MOLINA, Matías. Acción sindical argentina. El sindicalismo cristiano y su relación con la formación de la guerrilla urbana (1955-1976). En: www.scribd.com.

74 En el contexto de radicalización política y peronización de los sectores medios y universitarios, esta experiencia docente se desarrolló entre 1968 y 1972 en la Facultad de Filosofía y Letras de la Universidad de Buenos Aires, especialmente en la Carrera de Sociología. De orientación peronista de izquierda y tercermundista, sus docentes postularon el desarrollo de una ciencia articulada a los procesos de liberación nacional -en confrontación abierta con el cientificismo de la tradición germaniana-.

75 Fue Director del Instituto de Formación Social Sindical (IFSS) y del Instituto para la Educación y Capacitación de los trabajadores (ITEC); Secretario de Coordinación del Centro Argentino de Economía Humana (CAEH).

76 CARRI, R. Op. Cit., p.134.

77 Entrevista a J. Neffa, Op. Cit. 
socialización de los medios de producción. Lo decíamos con mucho cuidado porque el peronismo no era muy receptivo a esta clase de consignas, mas asociadas a la izquierda tradicional ( ) no es un movimiento de izquierda revolucionario por lo tanto había que tener mucho cuidado al hacer esta clase de sugerencias ${ }^{78}$.

En síntesis, aunque es necesario señalar que los vínculos personales e inorgánicos entre los distintos actores tornan difusas por momentos las delimitaciones realizadas $^{79}$, es claro que con distintos niveles de involucramiento y con diversos intereses y orientaciones, en estos años desde que la CGT fue normalizada y se inicia el Plan de Lucha, ninguna de las tendencias que hemos descripto relegaron su intervención en este espacio de disputa ideológica. A su vez, la complejidad de actores colectivos e individuales que allí circularon promovieron de hecho (aunque no hubiese sido pensado en ese sentido) un modo de construcción de conocimiento polifónico.

\section{Preguntas abiertas}

A partir de la experiencia relatada hemos visto cómo en un contexto de fuerte confrontación social, la educación obrera entendida como formación políticosindical lejos de ser soslayada fue terreno en disputa de las distintas corrientes político-ideológicas, sus referentes nacionales e internacionales. ¿Cuál fue el sentido del proceso de formación que encaró la CGT en aquellos años en que la tendencia revolucionaria dentro del peronismo comenzaba a cuajar organizativamente? Consideramos que fue justamente ese contexto particular el que habilitó la convivencia de tendencias que si bien se disputaban su influencia en América Latina -como fueron la CLASC y la ORIT-, compartían un límite común que era el anticomunismo.

Por lo general, los historiadores han prestado casi nula atención a la temática de la formación político-sindical, mientras que desde el campo de estudios que más ampliamente analizan las prácticas pedagógicas de los movimientos sociales, la mirada se posa sobre lo alternativo (en forma y contenido) a lo dominante. El Instituto de Capacitación y Formación Social Sindical en cambio no fue impulsado con fines emancipatorios ni revolucionarios, pero tampoco de reproducción de lo existente.

Esta tensión nos llevó a intentar pensar el interés de estos sectores sindicales (considerados burocráticos, reformistas, conciliadores, etc.) por impulsar un tipo de actividades educativas que priorizaban el ámbito sindical como un espacio de reelaboración y conceptualización política, advirtiendo el rol potenciador que podían llegar a cumplir las instancias sistematizadas de reflexión sobre la propia práctica, como parte del proceso de lucha impulsado.

Efectivamente, Plan de Lucha e Instituto de Capacitación y Formación Social Sindical no solo se combinaron temporalmente sino que se nutrieron y retroalimentaron

78 Entrevista a A. Borón. Op. Cit.

79 Por dar un ejemplo, A. Sily, autor utilizado como bibliografía básica por el docente J. Neffa, era un hombre cercano a N. Saleño y J. Alonso. Mientras que estos dos últimos terminaron vinculados al gobierno militar de la 'Revolución Argentina', el sacerdote posconciliar y docente de la Universidad Católica Argentina, fue declarado cesante por apoyar la protesta docente de la UBA en 1966. IZAGUIRRE, Inés. El mapa social del genocidio". En: IZAGUIRRE, Inés (Comp.). Lucha de clases, guerra civil y genocidio en la Argentina. 19731983. Buenos Aires: Eudeba, 2009, p. 79.

Lo mismo podría señalarse en relación a quienes posteriormente a pasar por la experiencia del ICFSS se vincularon a la CGT de los Argentinos, y/o fueron impulsores y docentes de las 'Cátedras Nacionales'; mientras que otros siguieron cercanos al sindicalismo participacionista. 
en términos de los contenidos teórico-prácticos impartidos, no sin contradicciones. La convicción en cuanto a la necesidad de una formación técnico-política para la acción político-gremial, con el fin de ocupar espacios de poder, así como el modo en que esta experiencia fue desarrollada sistemáticamente a pesar de ubicarse en un momento de algidez de la lucha de clases, nos llama a seguir complejizando sobre el sentido y los resultados de estas prácticas de formación. Resultará interesante confrontarlas con aquellas experiencias formativas desplegadas contemporáneamente -por las organizaciones de la 'Nueva Izquierda' en Argentina- con un horizonte político distinto -revolucionario-; las que a pesar de sus críticas a los partidos de la izquierda tradicional (en sus experiencias nacionales e internacionales), consideramos replicaron los modelos tradicionales de educación -priorizando como ámbito para la formación política de los activistas gremiales el 'partido', y los momentos de confrontación abierta como la mejor escuela de formación-.

Recebido em 01/05/2013

Aprovado em 17/05/2013 